Neurologia medico.chirurgica, 13:3 20, 1973

\title{
Fundoscopy of the Retinal Nerve Fiber Layer in Neurosurgical Practice
}

\author{
William F. Hoyt, M. D.*
}

\begin{abstract}
Summary
The retinal nerve fiber layer surrounding the optic discs provides a unique clinical opportunity to view directly pathologic changes in the neural components of a major sensory pathway in the brain. Minute changes in this ncural tissue are best seen in bright red-free light of a direct ophthalmoscope. This report, stressing the neurosurgical significance of peripapillary retinal signs, illustrates and discusses 1) how incipient papilledema obliterates the normally glistening highlights and striations of the nerve fiber layer before any recognizable change is seen in the optic disc, 2) how focal axon degeneration from acute and insidious forms of optic neuropathy causes multiple slit-like thinnings in the arcuate nerve fibers before any recognizable signs of pallor or functional change occurs in the optic nerve, 3) how atrophy, direct or transsynaptic, of an optic tract causes diagnostic homonymous patterns of axon loss in the peripapillary nerve fiber layer and optic disc of the two eycs, and 4) how recognition of fundoscopic signs of hemiretinal and optic hypoplasia allows the neurosurgeon to differentiate the bitemporal or homonymous hemianopias of developmental origin from the acquircd effects of brain tumor.
\end{abstract}

\section{Introduction}

Evaluation of optic discs for swelling or atrophy is an important part of everyday neurosurgical practice. When fundoscopic changes are advanced, they usually are seen and interpreted correctly. When the disc changes are subtle or marginal, the risk of misinterpreting them is a constant hazard. The need for more precise ophthalmoscopic indicators of incipient papilledema** and of early axonal degeneration challenges particularly the ophthalmologist who participates in the clinical evaluation of neurosurgical patients.

Retinal nerve fibers and their capillaries are the tissues of the optic discs that

Presented before the 32nd Annual Meeting of the Japan Neurosurgical Society, Fukuoka, October 19, 1973.

* Professor of Ophthalmology, Neurosurgery, and Neurology

Neuro-Ophthalmology Unit, Department of Neurosurgery, University of California-San Francisco

Reprint requests to Dr. Hoyt, 782 M, University of California, San Francisco, California 94143 USA.

** We restrict the term "papilledema" to that type of disc swelling which results from elevated intracranial pressure. The term "disc edema" is used for all other types of swelling, including idiopathic types. 
swell in papilledema and shrink in optic atrophy. Both of these tissues can be secn best where they form a semiopaque layer on the retina near the optic disc. In my neuroophthalmology unit at the University of California we have been studying the peripapillary nerve fiber layer of our patients using red-frce illumination for direct ophthalmoscopy and fundus photography. In the past few years we have learned to identify distinct changes in this layer that occur in incipient papilledema (Hoyt and Knight, 1973) and in retrograde axon degeneration of varying degrees and ctiology (Hoyt, Schlicke, and Eckelhoff, 1972; Hoyt, Frisén, and Ncwman, 1973; Hoyt, Rios, Behrens, and Eckelhoff, 1972; and Hoyt and Kommerell, 1973).

\section{Methods and Criteria for Evaluation of the Peripapillary Retinal Nerve Fiber Layer}

Filtering out of red wave lengths from light used in ophthalmoscopy enhances the visibility of superficial layers of the retina, accentuating the nerve fiber reflexes and finc vascular detail, as reported by Vogt in 1913, and later by Mizuno, Majima, Ozawa and Ito, 1968. Vogt described a special carbon arc light source and filter, developed by the Carl Zeiss Optic Company, that provided intense red-free illumination of the fundus. For our obscrvations of early papilledema and incipient optic atrophy we have been using a battery-powered direct ophthalmoscope that emits very bright red-free light through a green filter.

For documenting findings in the nerve fiber layer we use the Carl Zeiss fundus camera with its magnification attachment, and Kodachrome II color film. 'Transparencies are copied on Kodak Plus-X Pan film, using green (Wratten No. 65) filter. Black and white negatives are printed on Kodak Ektamatic photographic paper.

Factors aiding examination of the nerve fiber layer are a dilated pupil, clear optic media, exact focusing with the ophthlmoscope, and rich pigmentation of the fundus.

Appearance of the normal retinal nerve fiber layer near the disc. Only the peripapillary portion of the nerve fiber layer is thick enough to be seen consistently with the ophthalmoscope, or photographed. Here, the nerve fiber layer appears slightly opaque with a radial finely-striated pattern of superficial light reflexes. Near the disc the striations appear coarse and interweaving. Nerve fiber reflexes can be traced peripherally in the fundus for two to three disc diameters. Opacity of the layer is greatest where the arcuate bundles (fibers in the region of the superior and inferior temporal retinal vessels) cnter the superior and inferior poles of the disc. Nerve fiber reflexes are also easily seen on the nasal side of the disc, but they are more difficult to see on the temporal side because of the fine caliber of axons in the papillomacular bundlc. Proximal trunks of main retinal vessels are partially buried within the nerve fiber layer. Smaller vessels supplying nerve fibcr bundles appear blurred and crosshatched by overlying fibers (Figure 1 and 2 ).

Glossy reflexes from the surface of the youthful retina tend to obscure fine details. These reflexes change location and form with shifts in the angle of illumination. True nerve fiber striations do not change in this way. 


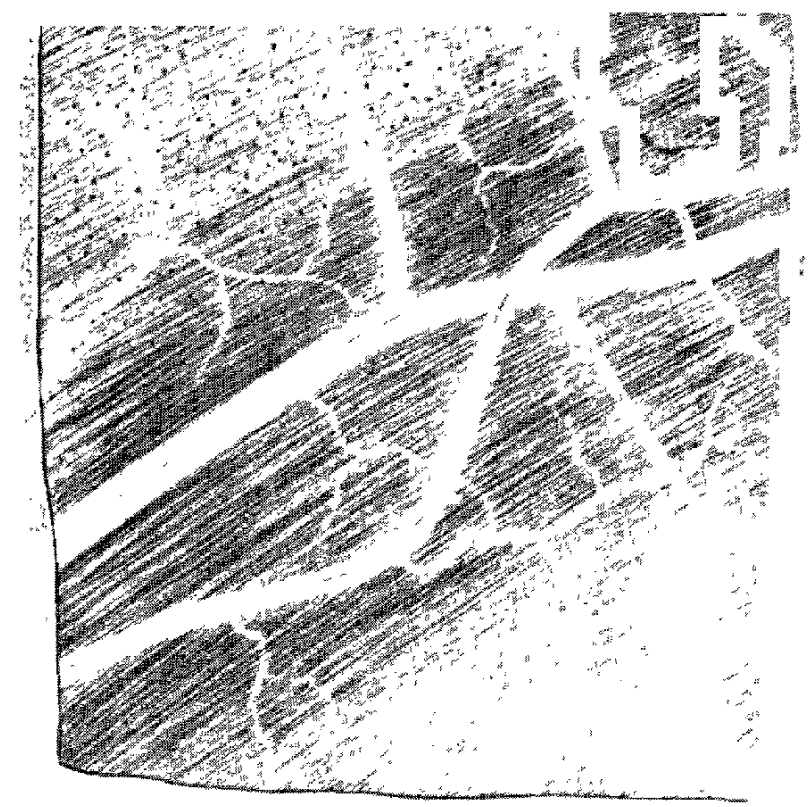

Fig. 1 Schema of the normal nerve fiber layer (near the left optic disc), showing how the uniform linear ncrvefiber striations blur and obscure the image of the small retinal vesscls.

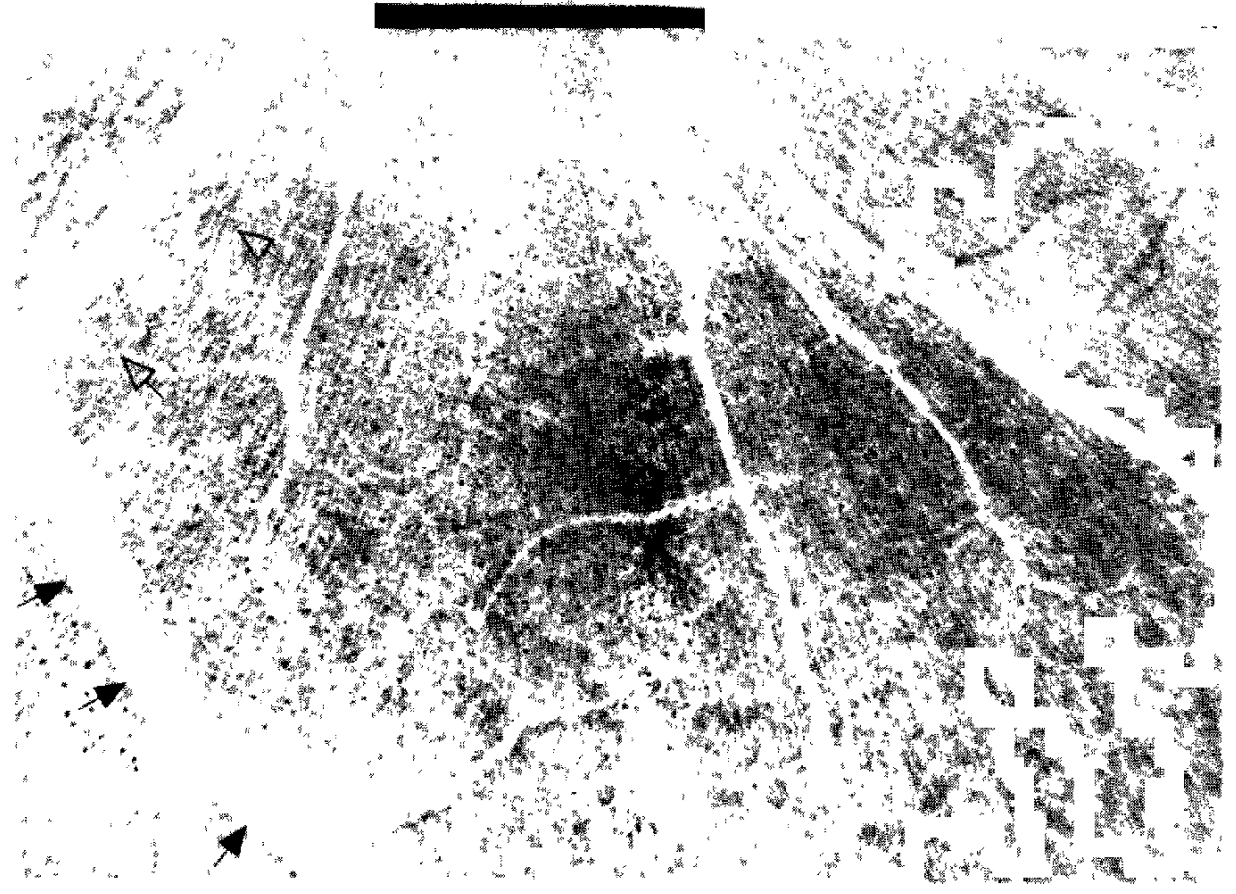

Fig. 2 Normal peripapillary retina in a red-free photograph from a 21-year-old girl. The features include 1) fincly-striated nerve fiber bundle reflexes, 2) semitranslucent appearance of nerve fiber layer with blurred nutrient vessels, 3) scattered point highlights, 4) bright vascular reflexes, and 5) a dark, perivenous gutter where the limiting membrane tents up over the vein (solid whitc arrows). Note the blurred appearance of the nerve fiber layer (beyond open white arrows), a constant feature where the thick arcuate bundles approach thc disc in company with the major temporal vessels. 


\section{Fundoscopic Differentiation of Congenitally Blurred Discs and Incipient Papilledema}

Comparison of the peripapillary nerve fiber layer in patients with congenitally blurred disc margins and in patients with early papilledema and elevated intracranial

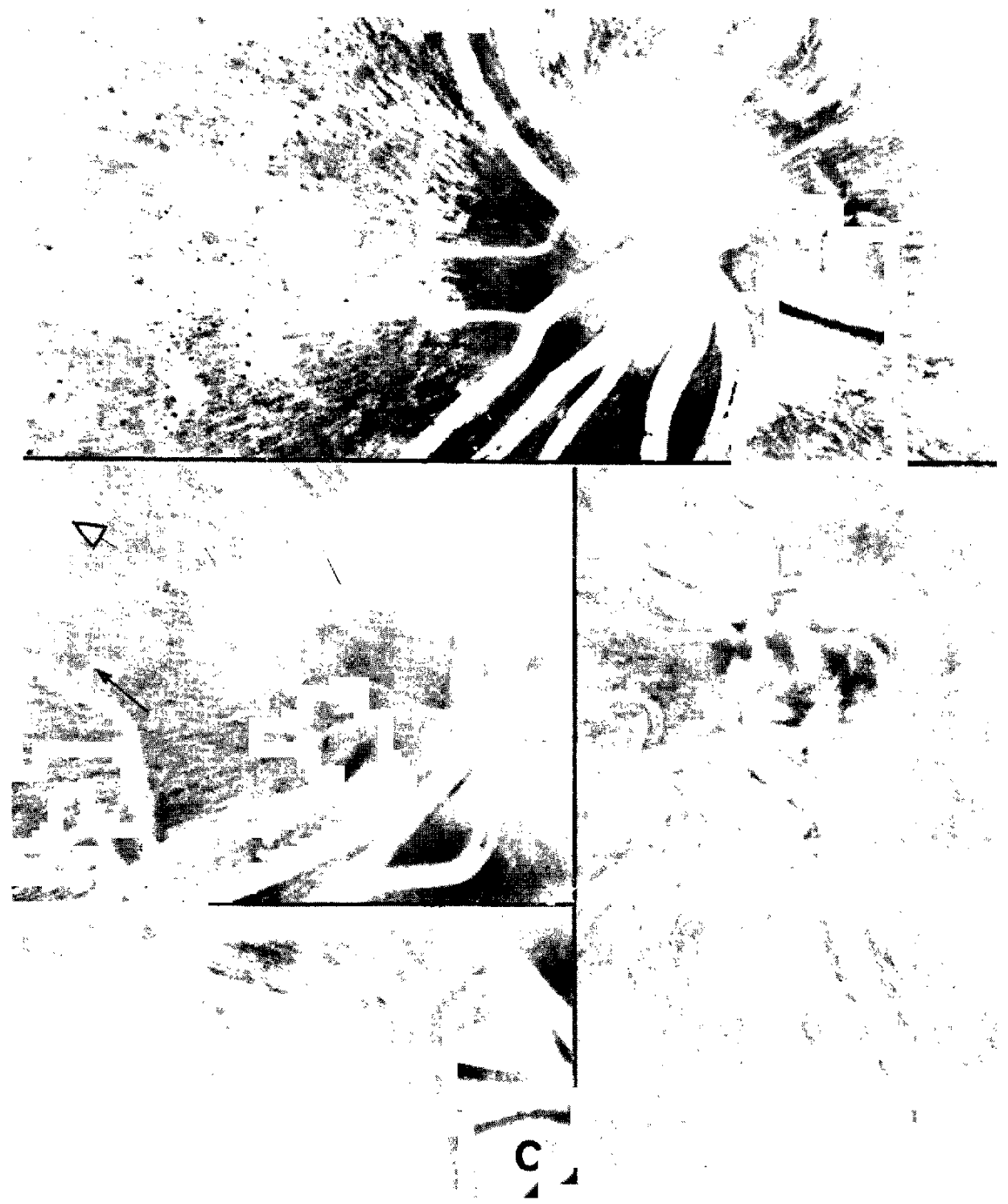

Fig. 3 Congenitally blurred optic disc margins. Notc finc, linear striations of nerve fiber bundles approaching disc margins (A, B, and C), the subsurface nutrient vessels, (B, arrows), and the glistening lincar light reflexes from the surface of arterial and venous blood columns (A, B, C, and D). 
pressure reveals marked differences in red-free (green) illumination. Fundi with congenitally blurred disc margins have typical features of a normal nerve fiber layer including a glossy, semitransparent appearance, glistening reflexcs on major blood vesscls, and fine, radially striated reflexes from the surface of the nerve fiber layer. These striations consist of numerous parallel discontinuous grey and white lines that partially obscure small nutrient vessels within the nerve fiber layer. The striations are clearly visible up to the disc margin, and occasionally crossing it (Figure 3, A-D).

In fundi of patients with incipient papilledema, the normal, finely striated pat-

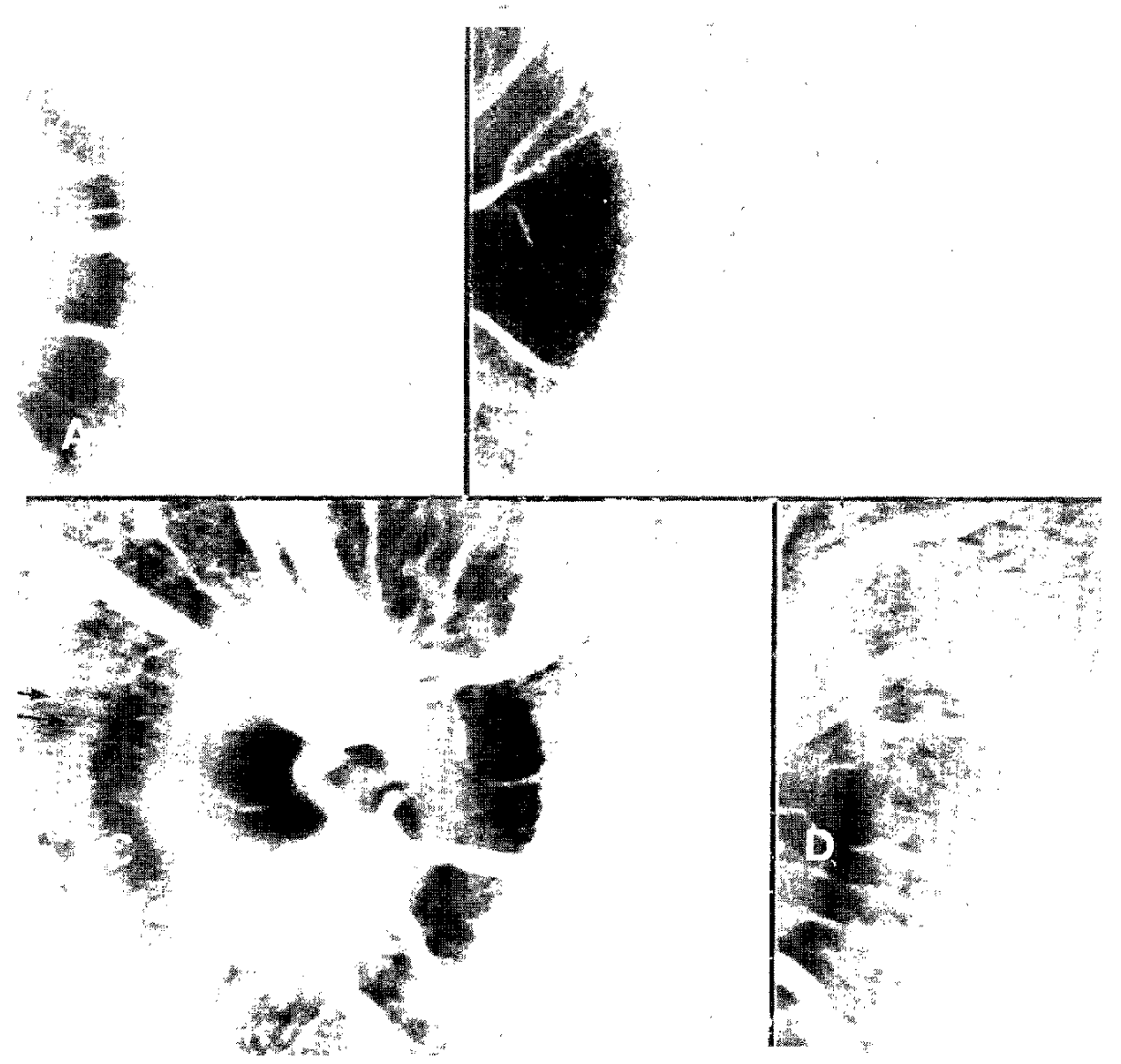

Fig. 4 Acquired blurring of disc margins and retina with incipient papilledema. Intracranial pressure was clevatcd in each patient. Note the generally blurred appearance of all surface details from the nerve fiber layer. All fine striations are obliterated. The coarse curvilinear reflexes (B) represent abnormal wrinkling of the inner limiting membrane. Other superficial retinal reflexes are also absent, and subsurface nutrient vessels are hidden. Most major vessels have lost their surface reflexes and appear uniformly dark and dull. 
tern of nerve fiber bundles are erased completely, or replaced by blurred white dots and short lines that give only a hint of nerve fiber bundles. The entire retina about the disc looks abnormally dark and featureless, as if out of focus. Artcries, and particularly veins, have no light reflexes, and appear dark; veins are usually tortuous and enlarged. Margins of the discs are obscured by grey and white dots, perhaps related to the dilated radial capillary network. Subsurface nutrient vessels are almost invisible in the dull, reflex-poor retinal nerve fiber layer (Figure 4, A-D).

Thus we find clear fundoscopic differences between congenital disc blurring and the blurring of incipient papilledema. The normal peripapillary retina with disc

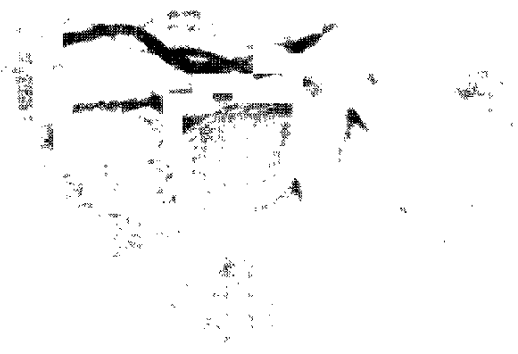

\section{Papilledema}

\section{Papillitis}

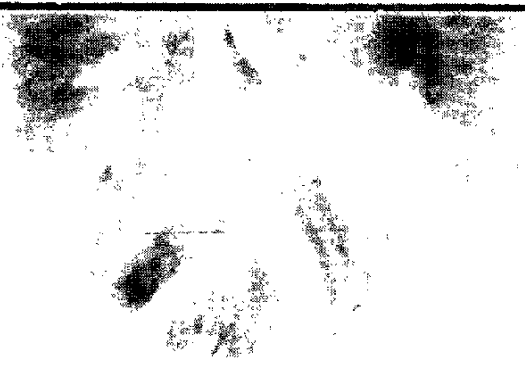

Fig. 5 Equivalent disc swelling in papilledema and papillitis. Note the difference in the peripapillary retinac. Striated nerve fiber reflexes are clearly visible in papillitis but cannot be seen in papilledema. In papillitis, the nerve fiber layer vessels ( 3 white arrows) are easily seen while in papilledema they are obscured. The veins are enlarged in both conditions but the retinal vascular highlights are retained in papillitis. 
blurring has sharply defined, glittering light reflexes from nerve fiber bundles, vessels, and inner limiting membrane. The abnormal peripapillary retina with early papilledema appears dark red and lusterless, with loss of most light reflexes from the surface of the nerve fiber layer and blood vessels. It is these differences in specular reflection of the retina, not the disc margins per se, that distinguish incipient papilledema from its congenital imitators. Although visual symptoms accompanying papillitis eliminate it from practical consideration in the differential diagnosis of incipient papilledema, differences in the red-free appearance of the peripapillary nerve fiber layer in the former are noteworthy; in papillitis the striated reflexes of the nerve fiber layer are clearly seen (Figure 5).

Comparison of color fundus pictures of incipient papilledema and congenitally blurred discs shows more redness of the peripapillary zone in papilledema. Here the color shifts toward a highly saturated, purple hue, obscuring details of the underlying choroid. We believe the diffuse redness indicates increased blood volume in both retinal and choroidal capillaries, and effects of venous stasis. In Poland, Szapiro and Swietliczko (1965) have documented the way in which certain hemodynamic factors in patients with intracranial hypertension influence the color and transparency of the retina. They studied the ocular fundi preoperatively in anesthetized neurosurgical patients before and 15-30 minutes after hyperventilation. Before hyperventilation, their patients' retinac appcared dark red and lusterless (as we have noted with incipicnt papilledema). After hyperventilation, their patients' retinal venous pressure dropped strikingly, venous caliber diminished, and the peripapillary retinae regained the normal glistening superficial highlights, striations, and lighter color.

Differential diagnosis of subtle disc blurring, as documented repeatedly in our studies, can be made at the patient's bedsidc with red-free ophthalmoscopy. With a dilated pupil and with practicc, normal nerve fiber striations are easily seen. When present, they cxclude congestive edema in the nerve fiber layer and immediately identify the normally hydrated, congenitally blurred disc, a finding that argues strongly against elevation of intracranial pressure.

\section{Fundoscopy of Focal and Diffuse Atrophy of the Nerve Fiber Layer in Patients with Optic Nerve Damage}

Atrophy of the retinal nerve fiber layer, in early and late stages, can be recognized by criteria that we have described recently (Hoyt, Schlicke, and Eckelhoff, 1972; Hoyt, Rios, Behrens, and Eckelhoff, 1972), especially in a study of glaucomatous eyes (Hoyt, Frisen, and Newman, 1973).

Dark slits and wedges in the peripapillary nerve fiber layer indicate focal loss of visual axons. These slits, or bands, of thinned or absent nerve fiber tissuc appear redder than adjacent, normal tissue in regular ophthalmoscopic illumination and darker in redfree (green) light; hence such defccts are more easily seen when red-free light is used. Full-thickness slit or wedge defects have no nerve fiber reflexes within their borders. Slit defects have maximum contrast in the thick zones of the nerve fiber layer, specifically in the superior and inferior arcuate (temporal) zones of the retina. With increasing distance from the optic disc, these defects successively lose contrast. Slits 


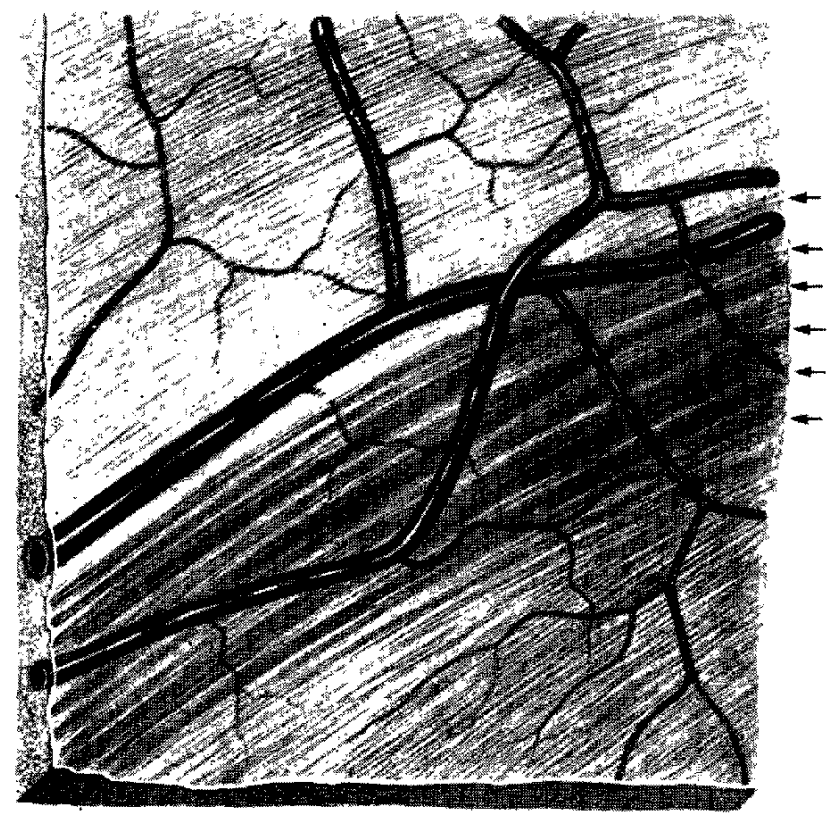

Fig. 6 Schema of slit-like defects among the superior arcuate nerve fiber bundles (ncar the disc in the left fundus).

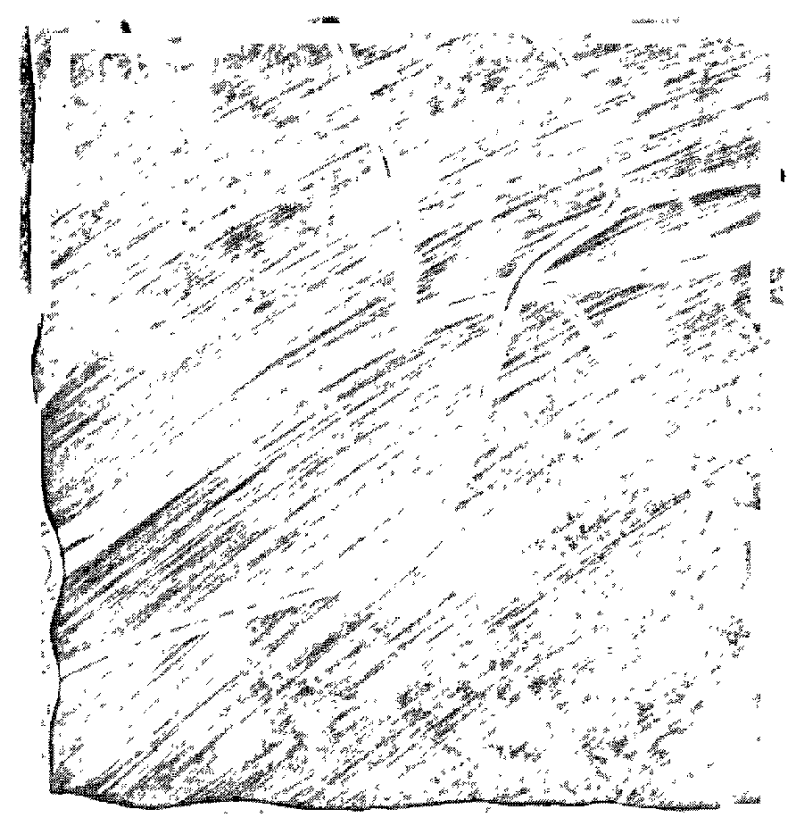

Fig, 7 Schema of diffuse atrophy showing decreased striations in the thinned nerve fiber layer, and increased clarity of retinal vessels. 
taper and vanish from sight among the crowded interweaving fiber bundles approaching the disc margin. Slits usually show up first among the upper arcuate bundles regardless of the cause of the optic nerve involvement. They first appear one to two disc diameters away from the nerve head, and when multiple, they impart a "raked" appearance to the nerve fiber layer (Figure 6).

Exposure of small vessels as they cross slit or wedge defects causes the vessel to look darker and its surface reflex brighter. If atrophy is severe in the nerve fiber layer, all vessels stand out sharply in relief. Linear light reflexes from such exposed vessels are continuous and bright.

Diffuse thinning of the nere fiber layer around the opticdisc is difficult to recognize in

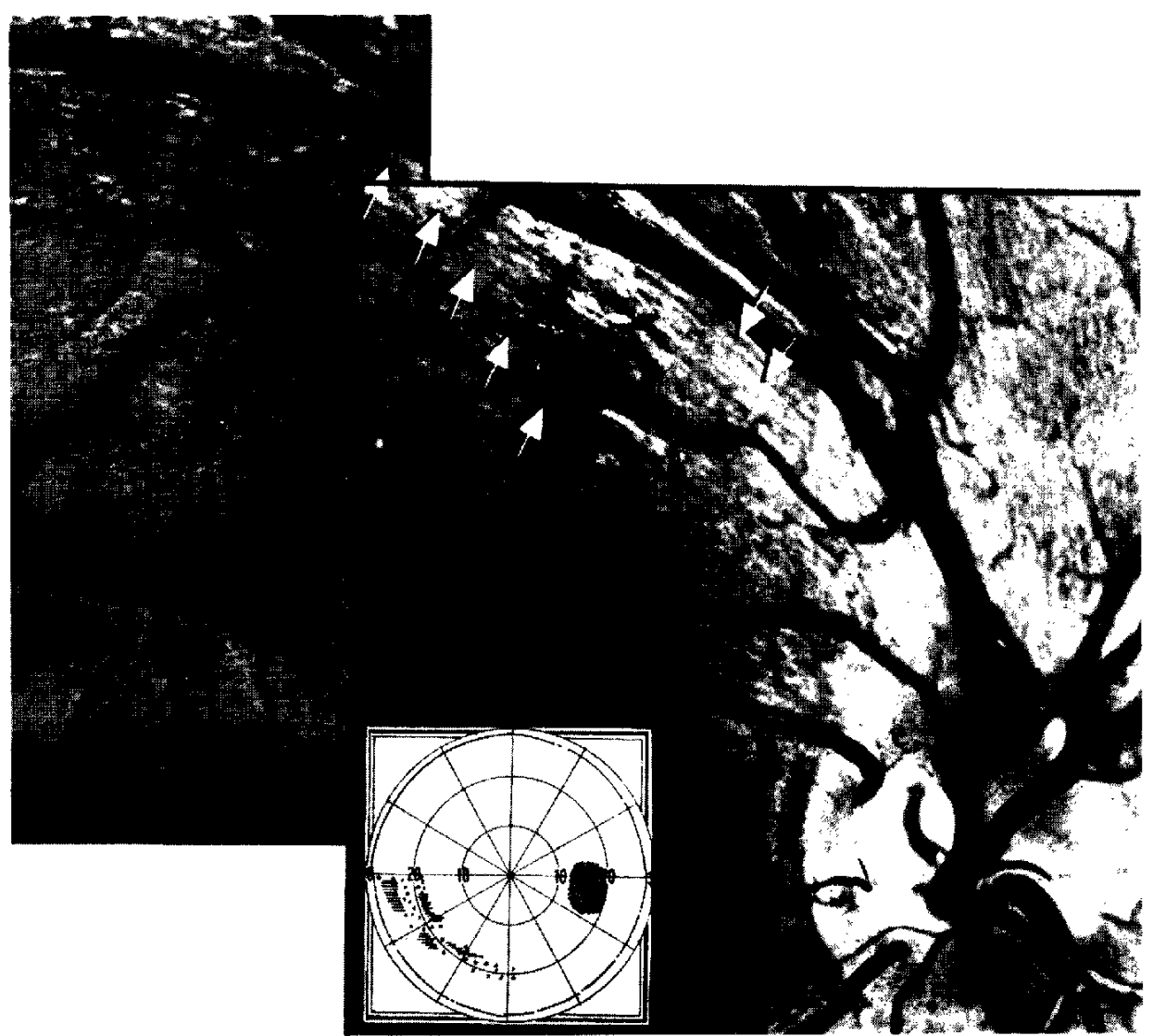

Fig. 8 Early nerve fiber layer defects in an cye with glaucoma. Note parallel dark slits below the main trunk of the superior retinal venule (arrows). The slits can be followed proximally from just beyond a vertical line through the macula (to the left of the figure), to where they fade out in the thick fiber layer above the disc.

Pcrimetric evidence of nerve fiber abnormality was obtained only with a $2 / 2000 \mathrm{~mm}$ white test object. The field defect (inset) consisted of spotty, relative scotomas and on-andoff blinking in the lower nasal half of the arcuate zone. 
early stages of axonal depletion. In more advanced stages signs of atrophy include decreased opacity of the arcuate fiber bundles, enhanced linear highlights on large and small retinal blood vessels, reduced caliber of blood vessels, and pallor with decreased capillarity of the optic disc tissue. Diffuse thinning of the fiber laycr accompanies focal atrophy (slit defects) sooner or later, and causes reduced contrast of slit defects, reduction of nerve fiber striations, and a darker appcarance in red-frec light of the underlying retina and choroid (Figure 7).

Visible signs of nerve fiber atrophy in the retina can be correlated with defects in the field of zision. local (slit-like) defects in the nerve fiber layer should always be verified by examination of the patient's field of vision, using techniques appropriate for demonstrating small relative paracentral and arcuate scotomas. For this purpose we prefer the Bjerrum (tangent) screen. Early slit-like defects in the nerve fiber layer produce narrow elongated scotomas situated between $20^{\circ}$ and $25^{\circ}$ from fixation (Figure 8). Such scotomas are identified as zones in which a slowly moved test object seems to the patient to flicker on and off. Thinning and focal atrophy of the papillomacular bundle should have corollary defects in central vision. Subtle changes in central vision can be identified by searching for areas of subjective color desaturation near fixation on the tangent screen, cxamination of color vision with pseudo-isochromatic plates, and by determining the patient's corrected visual acuity for low contrast letters read rapidly on a distance acuity chart.

Our fundoscopic and perimetric correlative studies in patients with vascular, glaucomatous, and demyelinating optic ncuropathies indicate that a nerve fiber bundle defect, previously only a clinical perimetric concept, is an objective sign that can be seen with a hand ophthalmoscope in red-free illumination. The presence of such defects always signifies permanent loss of visual axons even in patients without previous history of optic nerve disease. For example, we have documented signs of focal axon degencration in the arcuate nerve fiber bundles in the fundi of patients with brainstem or spinal cord manifestations of multiple sclerosis; these patients had corresponding arcuate scotomas in their visual fields but had not been aware of optic nerve symptoms at any time. The optic discs can appear perfectly normal in such patients. The occurrence of visible nerve fiber atrophy in eyes of patients with multiple sclerosis is objective evidence that some demyelinating lesions insidiously destroy axons in combination zeith their myelin sheaths (Figure 9).

While fundoscopic examination of the nerve fiber layer cannot localize a lesion causing focal atrophy of axon bundles, the examination findings (slit-like nerve fiber defects) can establish the "second" lesion in patients with an acute brainstem or spinal cord syndrome. Recognition of these subtle ocular signs strengthens the clinical diagnosis of multiple sclerosis and cancels need for neuroradiologic studies to exclude tumor (Frisén and Hoyt, 1974).

Close inspection of peripapillary retinal nerve fiber striations and vascularity is now routine in our evaluation of patients with visual failure from parasellar tumors. If the nerve fiber layer appears normal despite gradual loss of vision in an eye, we are optimistic that surgical decompression of the nerve will promptly restore most of its function. If fundoscopic examination shows extensive diffuse axon loss in the nerve fiber layer, we are pessimistic that neurosurgical decompression of the nerve can restore useful vision in the affected eye. 


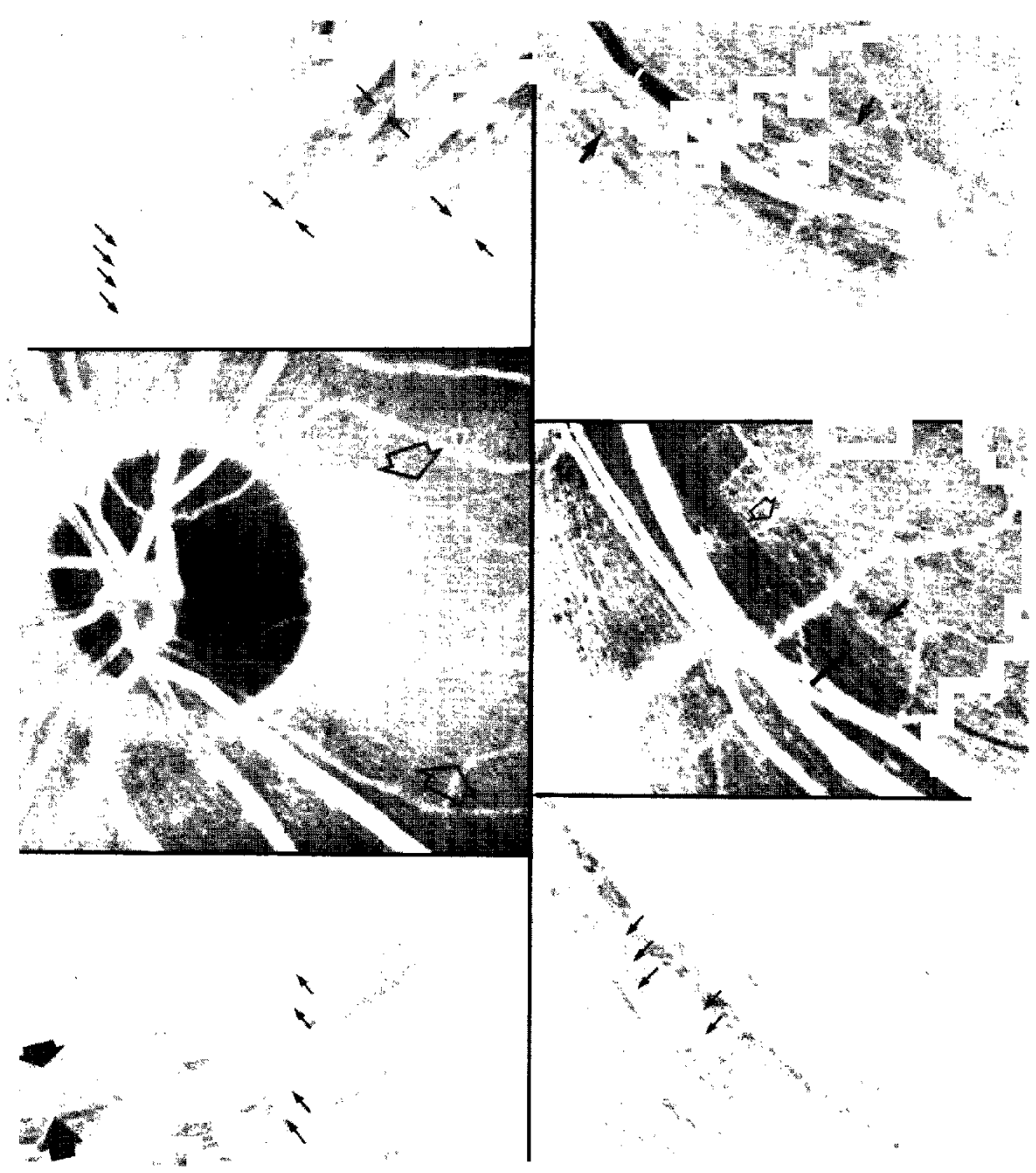

Fig. 9 Early nerve fiber layer defects in patients with demyelinating optic ncuropathy from multiple sclerosis. All photographs, except the one including the optic disc, show "slit" or "band" defects in the arcuate fiber bundles (solid white arrows). Small vessels are better defined where they cross defects (upper right, and middle right, open arrows). The photograph with the optic disc shows the appearance of the peripapillary retina in a young patient with 20/40 vision and defective color perception. Note the apparently normal arcuate fiber bundles. The nerve fiber layer is invisible temporally (between the white arrows), where small vessels are decreased in number and their light reflexes abnormally distinct. Temporal pallor of the optic disc is marginal. 


\section{Patterns of Atrophy in the Retinal Nerve Fiber Layer of Patients with Homonymous and Bitemporal Hemianopias}

Atrophy of visual fibers in an optic tract produces retrograde nerve fiber degeneration of crossed and uncrossed fibers in the chiasm, and anatomically predictable patterns of nerve fiber loss in the contralateral and ipsilateral eyes (Figure 10). $\Lambda \mathrm{L}$ though retrograde homonymous hemiretinal changes were clearly shown in the histologic studies of Van Buren (1963), these retinal changes elluded detection with the ophthalmoscope. Paleness of the discs remained the only sign of axon degeneration of an optic tract in patients with long-standing homonymous hemianopia (Wilbrand and Saenger, 1917). Lauber reported briefly the patterns of retinal atrophy that he had observed in a paticnt with a chronic optic tract lesion. For his obscrvations he

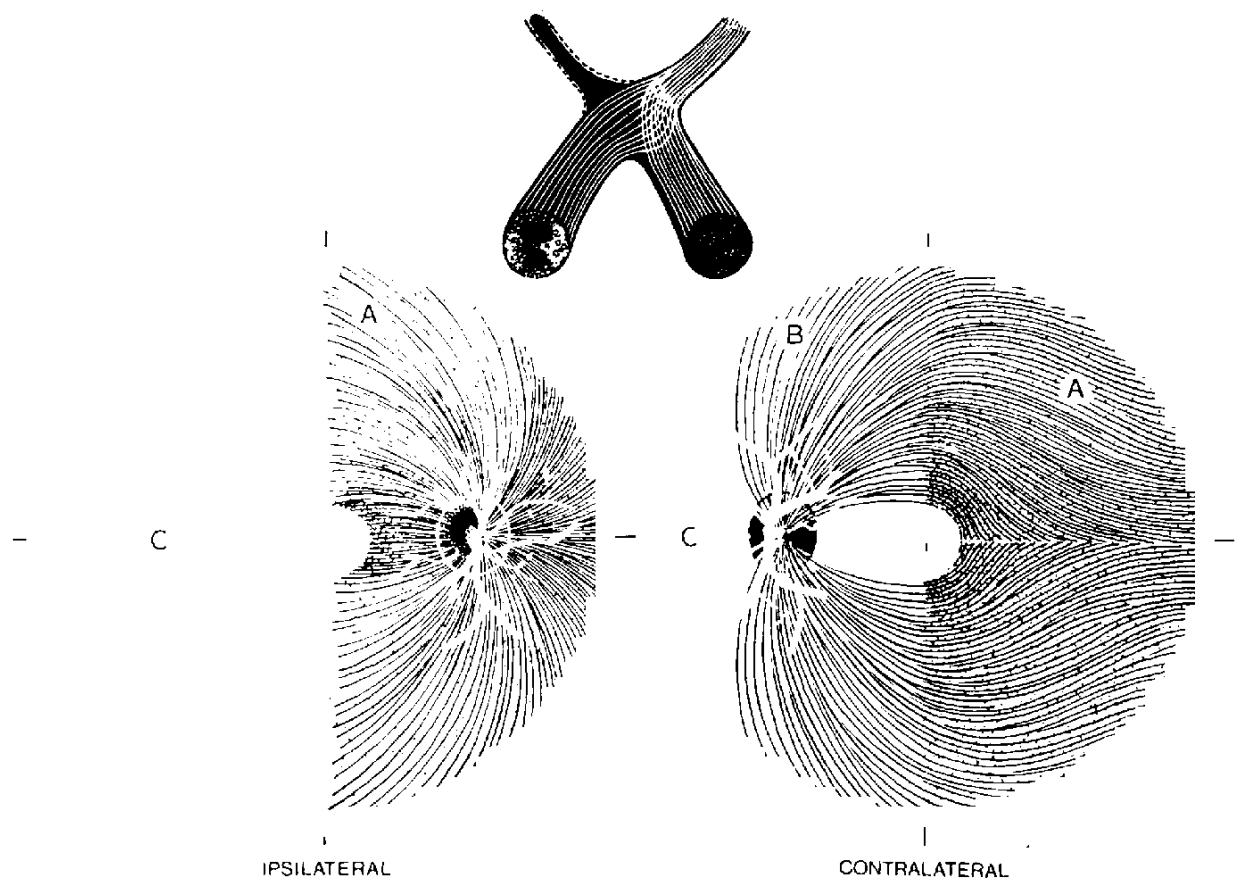

Fig. 10 Diagram of the pattern of nerve fibcr atrophy from a right optic tract lesion. The atrophic portions in the chiasm. optic nerves and fundi are indicated in black. In black areas of the retinae ( $\mathrm{C}$ ) there are neither ganglion cells nor nerve fibers. The "seeing" halves of the retinas. (A) contain both ganglion cells and nerve fibers. Traversing part of the "blind" nasal hall ol the retina in the left eye (B), there are nerve fibers but no ganglion cells.

Note the band-shaped pattern of disc pallor in the left ocular fundus (the contralateral eye), and note the oval temporal zone of disc pallor in the right fundus (the ipsilateral eye).

Nerve fiber atrophy in the ocular fundi and the pattern of disc pallor are the same, but less obvious, in patients with congenital retrogeniculate hemianopias. 

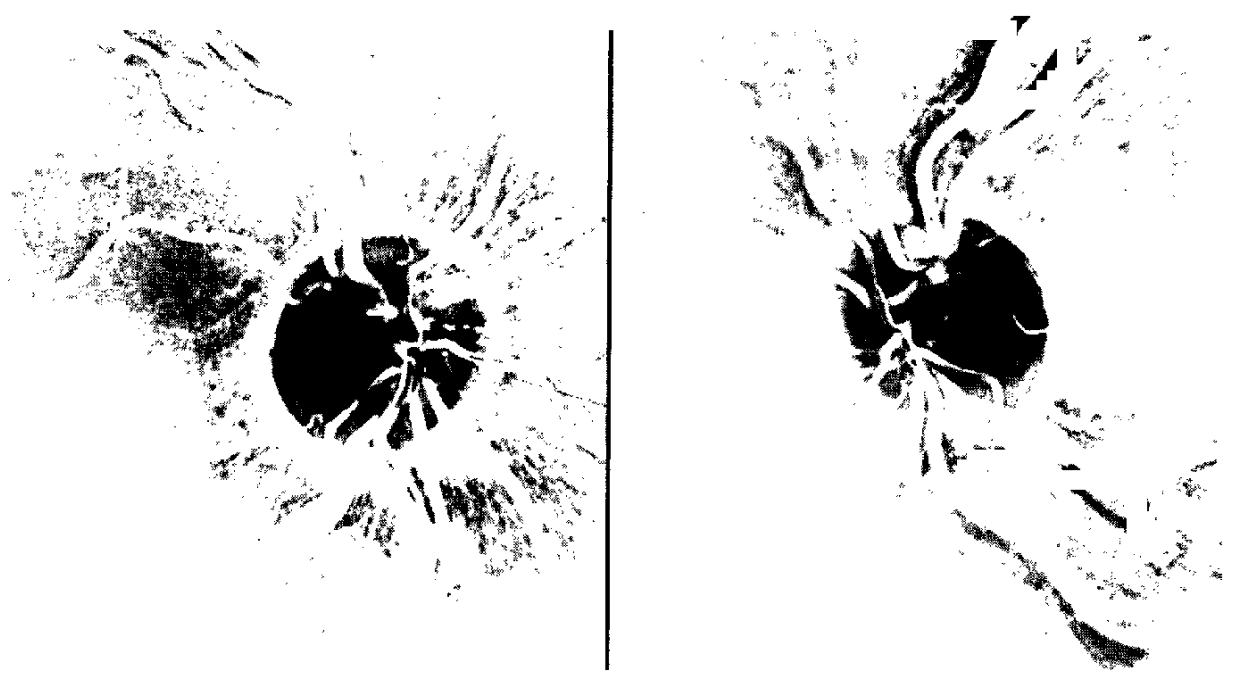

Fig. 11 Homonymous hemiretinal patterns of nerve fiber loss after trans-synaptic degencration from a lesion in the right retrogeniculate pathway. Compare the nerve fiber patterns in the two eyes with the diagram of optic tract atrophy, Figure 10.
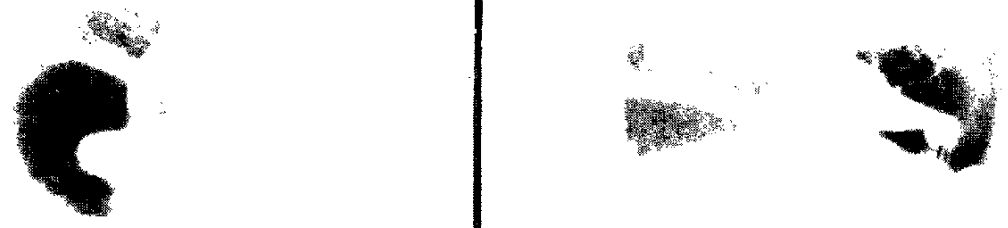

\section{R T}

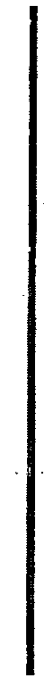

\section{LT}

Fig. 12 Patterns of disc pallor from right-sided optic tract lesion. The contralateral disc (Lt) shows horizontal "band pallor". The ipsilateral disc (Rt) is pale temporally. The patient accuired left homonymous hemianopia following operation for a basal meningioma. 
used red-free illumination as advocated by Vogt (1917). By photographic techniques we now have documented these hemiretinal patterns of nerve fiber atrophy (and the corresponding patterns of disc pallor) in patients with chronic optic tract lesions and even retrogeniculate lesions, when the latter were perinatal in origin (Hoyt and Kommerell, 1973).

In patients with optic tract atrophy, pallor in the contralateral disc occupies a transverse band ("band pallor"). In trans-synaptic atrophy the pattern is the same, but less obvious. Ipsilateral disc pallor (on side of tract lesion) is also distinctive; it is temporal and more pronounced centrally than near the disc margin (Figure 11). The contralateral eyes with a blind nasal hemiretina have arcuate nerve fiber reflexes above and below the disc but have no visible nerve fibers in retinal sectors on the nasal or temporal side of the disc (Figure 12). Here the retinal sectors are darker, more avascular, and devoid of striated reflexes. In ipsilateral fundi, in which the tempo-

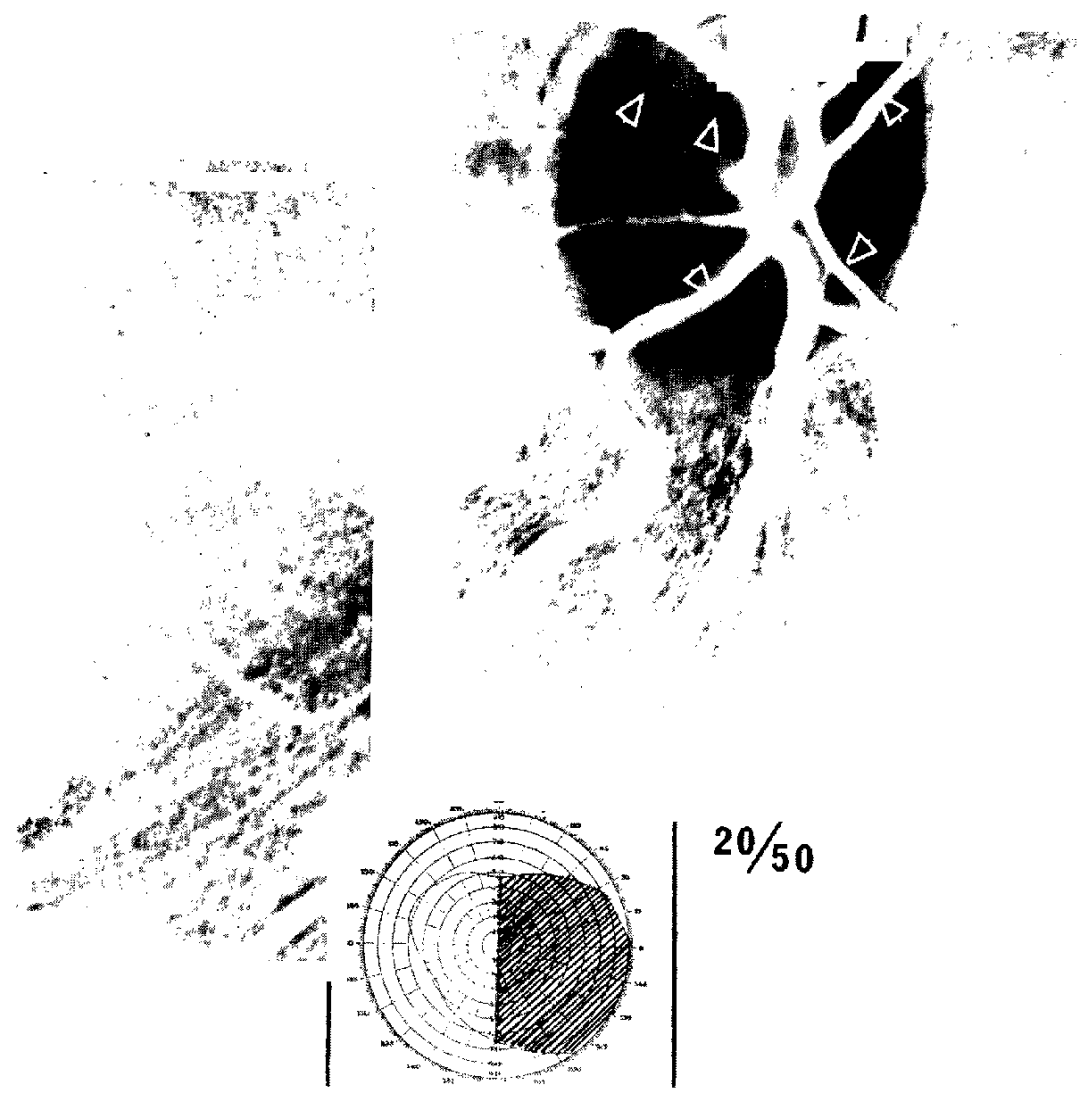

Fig. 13 Right optic disc with "band-pallor" (arrows) and loss of all nerve fibers and ganglion cclls from the nasal hemirctina. The visible nerve fibers, seen below the disc, come from the functioning temporal hemiretina. This is the fundoscopic counterpart of temporal hemianopia, acquired in this case from a giant left-sided carotid-ophthalmic aneurysm. 
ral hemiretina is blind, nerve fiber striations surround the disc but the nerve fiber layer is thinner than normal in the superior and inferior arcuate zoncs; linear highlights on trunks of major blood vessels are continuous and clearly seen in the temporal retina, suggesting atrophy of overlying nerve fiber tissue (Figure 13).

Recognition of these acquired hemiretinal patterns of nerve fiber and ganglion cell atrophy is useful in neurosurgical diagnosis. The findings signify that the patient's hemianopia has been present for months (in patients with optic tract lesions) or since infancy (in patients with retrogeniculate lesions). If homonymous hemianopia is discovered immediately after head injury, seizure, or hemorrhage from arteriovenous malformation, the finding in the eyes of homonymous hemiretinal atrophy indicates that the hemianopia predated the patient's acute illness.

If a patient is comatose, examination of the retinal nerve fiber layer is the only clinical method by which atrophy of an optic tract could be detected.

If a young child has a long-standing hemiparesis, the finding of "band pallor" of the disc on his paretic side indicates a temporal hemianopia in that eye and strongly suggcsts an accompanying nasal hemianopia in the fellow eye.

If "band pallor" and the corresponding pattern of retinal nerve fiber atrophy is found in both eyes, the patient has bitemporal hemianopia of long standing. This objective evidence of a chronic chiasmal syndrome is particularly valuable in the evaluation of a comatose patient with subarachnoid hemorrhage.

\section{Hemiretinal Atrophy and Hemioptic Hypoplasia in Children with Congenital Hemiplegia or Growth Retardation}

Homonymous hemiretinal patterns of atrophy in the optic fundi are frequent findings in children with congenital hemiplegia from cerebral hemiatrophy, porencephaly, and other congenital hemispheric delects. These fundoscopic signs and associated hemioptic hypoplasia were first reported in 1972 from our neuroophthalmology unit (Hoyt, Rios, Behrens, and Eckelhoff). Such children usually have epilepsy, a small spastic arm, and irregular nystagmoid eye movements that mask the presence of a homonymous hemianopia. In the eye opposite the atrophic hemisphere we find atrophic nerve fiber patterns indicating temporal hemianopia, and an undersized optic disc in which the nasal rim is pale and clcarly exposed. In thesc patients, the brain defect could have occurred before, during, or after birth. One clue to the time of onset of the brain injury is the size of the discs; if the size is almost normal, the "injury" occurred near the time of birth. If the disc size is markedly decreased, it can be assumed that the brain injury occurred relatively early in development. In some of these children it has been possible to observe hemiretinal changes at the macula. We term the optic system changes homonymous hemioptic hypoplasia (the $\mathrm{HHH}$ syndrome).

Another group of children with congenital hemianopic field defects (homonymous or bitemporal) and bilateral optic nerve hypoplasia (Figure 14) (greater in degree than in the HHH syndrome) have retarded growth, peculiar irregular nystagmus, and nearly normal central visual acuity in at least one eye. Some have congenital bitemporal hemianopia; a few have homonymous hemianopia. Because of the 


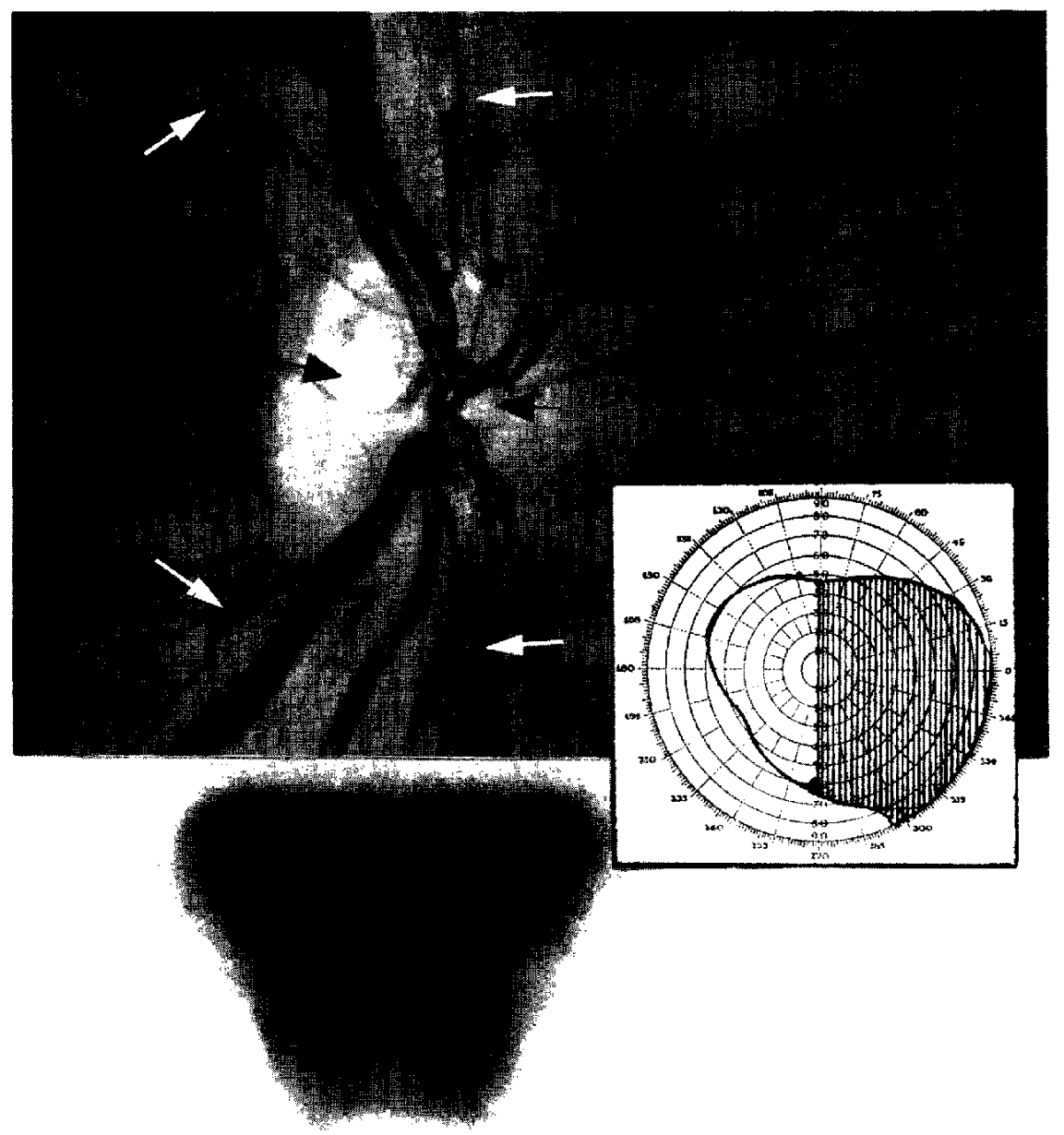

Fig. 14 Hypoplastic optic disc in scpto-optic dysplasia (1) Morsier's syndrome). The margin of the nerve is indicated by black arrows. The nasal half of this disc is grossly deficient. The white halo around the disc is exposed sclera. The only nerve fibers entering the disc arrive from the temporal hemiretina. They are barely visible above and below the disc (between the white arrows).

This eye has temporal hemianopia with visual acuity of $20 / 60$. Findings in the left eye were similar. The patient was an 8-year-old dwarfed boy. Pneumoencephalograms showed absence of the septum pellucidum (demonstrated in coronal tomographic section below), absence of the chiasmatic and hypophyseal recesses of the third ventricle, and small hypoplastic optic nerves. 
pallor of the optic discs, small stature, and occasionally diabetes incipidus, these children's manifestations are often misintcrpreted as evidence of congenital brain tumor. For this reason they are referred to a neurosurgeon. Instead of tumor pneumocncephalography shows absence of the seplum pellucidum! In 1953, De Morsier reported small optic nerves with this brain anomaly in his ncuropathologic study, and termed it "scpto-optic dysplasia". In 1970 we recognized this syndrome in children referred to our unit for cvaluation of congenital amblyopia, nystagmus, and unexplained pituitary dwarfism (Hoyt, Kaplan, Grumbach, and Glaser, 1970). Septooptic dysplasia is not rare (Brook, Sanders, and Hoare, 1972). It usually is given an incorrect diagnostic designation such as congenital optic atrophy, dwarfism with low vision, cerebral palsy, etc. Familiarity with the syndrome and its key signs - bilateral optic hypolpasia with hemianopic visual defects-allows the neurosurgeon to differentiate clinically in a young patient with disc pallor and bitemporal field defects whether the signs indicate congenital malformation or tumor.

\section{References}

1) Vogt, A.: Die Nervenfaserstreifung der menschlichen Netzhaut mit besonderer Berücksichtigung der Differentialdiagnose gegenüber pathologischen streifenförmigen Reflexen (prärctinalen Fältclungen). Klin. Mbl. Augenhlk. 58: 399. 411, 1917.

2) Mizuno, K., Majima, A., Ozawa, K., and Ito, H.: Red-free light fundus photography. Invest. Ophthahmol. $7: 241-249,1968$.

3) Hoyt, W. F., and Knight, C. L.: Comparison of congenital disc blurring and incipient papilledema in red-free light-a photographic study. Invest. Ophthalmol. 12: 241-247, 1973.

4) Hoyt, W. F., Schlicke, B., and Eckelhoff, R. J.: Fundoscopic appcarance of a nerve fibre bundle defect. Brit. J. Ophthalmol. 56: 577-583, 1972.

5) Hoyt, W. F., Frisén, L., and Newman, N. M. : Fundoscopy of nerve fiber layer defects in glaucoma. Invest. Ophthalmol. (in press for 1973).

6) Hoyt, W. F., Rios-Montenegro, E. N., Behrens, M. M., and Eckelhoff, R. J.: Homonymous hemioptic hypoplasia: Fundoscopic features in standard and red-free illumination in three patients with congenital hemiplegia. Brit. J. Ophthalmol. 56: 537-545, 1972.

7) Hoyt, W. F, and Kommerell, G.: Der Fundus oculi bei homonymer Hemianopie. Klin. Mbl. Augenhlk. 162: 456-464, 1973.

8) Szapiro, J., and Swietliczko, I.: Studies on the influence of some factors on papilledema. Proceedings Third Intcrnational Congress in Neurologic Surgery, Amsterdam, 1965, Lxcerpta Medica.

9) Van Buren, J. M.: 'Trans-synaptic retrograde degeneration in the visual system of primates. J. Neurol. Neurosurg. and Psychiat. 26: 402-409, 1963.

10) Wilbrand, H., and Sacnger, A.: Die Neurologie des Auges Vol. 7, Bergmann, Wiesbaden 1917 , p. 466.

11) Lauber, H.: Die ophthalmoskopische Differentialdiagnose der infra-und supranukleären Hemianopsie, zugleich ein Beitrag zur Topographie der Fascrverteilung in der Netzhaut. Ber. 46 Zusk. Dtsch. Ophth. Ges. Heidelberg 1927, p. 89-94.

12) De Morsier, G.: Etudes sur les dysraphies cranioencéphaliques. III. Agénésie du septum lucidum avec malformation du tractus optique. La dysplasie septo-optique. Schweiz. Arch. Neurol. Neurochir. Psychiat. 77: 267-292, 1956. 
13) Hoyt, W. F., Kaplan, S. L., Grumbach, M. M., and Glaser, J. S.: Septo-optic dysplasia and pituitary dwarfism. Lancet 1: 893, 1970.

14) Brook, C. G. D., Sanders, M. D., and Hoare, R. D. : Septo-optic dysplasia. Brit. Med. J. 3: 811-813, 1972. 